Institute of

Technical Thermodynamics
Towards Understanding the Dual Membrane Fuel Cell (IDEAL-Cell) Using a Metallic Central Membrane

\section{Dual Membrane Fuel Cell}

\section{Measurement set-up}

- BCY15 ( $\left.\mathrm{BaCe}_{0.85} \mathrm{Y}_{0.15} \mathrm{O}_{2.925}\right)$ and YDC15 $\left(\mathrm{Ce}_{0.85} \mathrm{Y}_{0.15} \mathrm{O}_{1.9}\right.$ electrolytes contacted

with platinum paste and mesh, replacing the composite ceramic CM

- pellets were fabricated via cold pressing and sintering at $1300^{\circ} \mathrm{C} / 4 \mathrm{~h}$

- $N, B$ and $Y$ modes for voltage measurement

- WE and CE same, SeE and RefE change in each mode
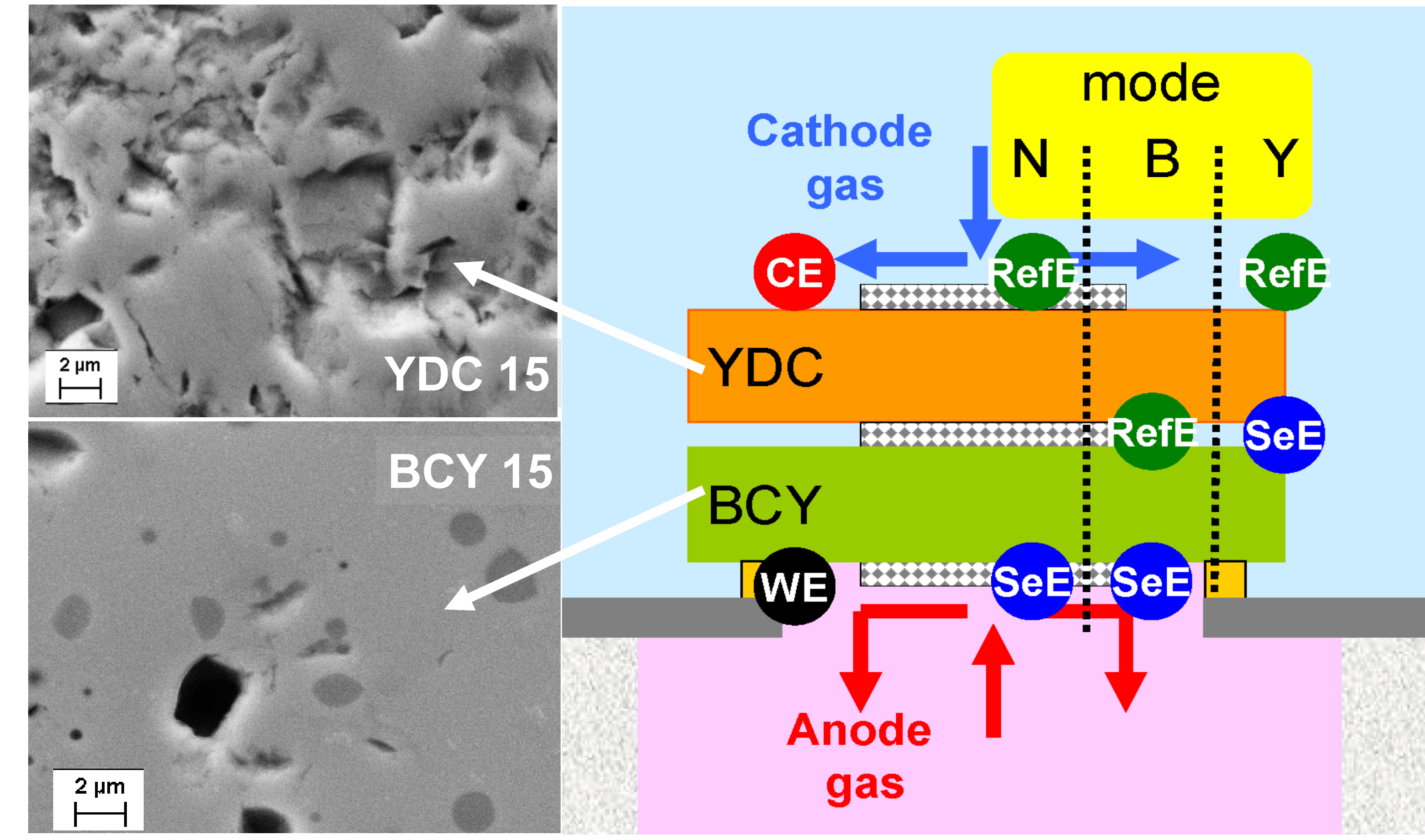

Micrograph of electrolytes

Electrode connections

\section{Results}

- measured BCY 15 conductivity as expected

- low conductivity was measured for YDC15

- phase instability in BCY 15 observed

- improved performance compared to PoC

- insufficient gas lead to higher LF resistance for both $\mathrm{N}$ and $\mathrm{b}$ modes

PoC sample is an all ceramic dual cell tested for proof of concept

1.2
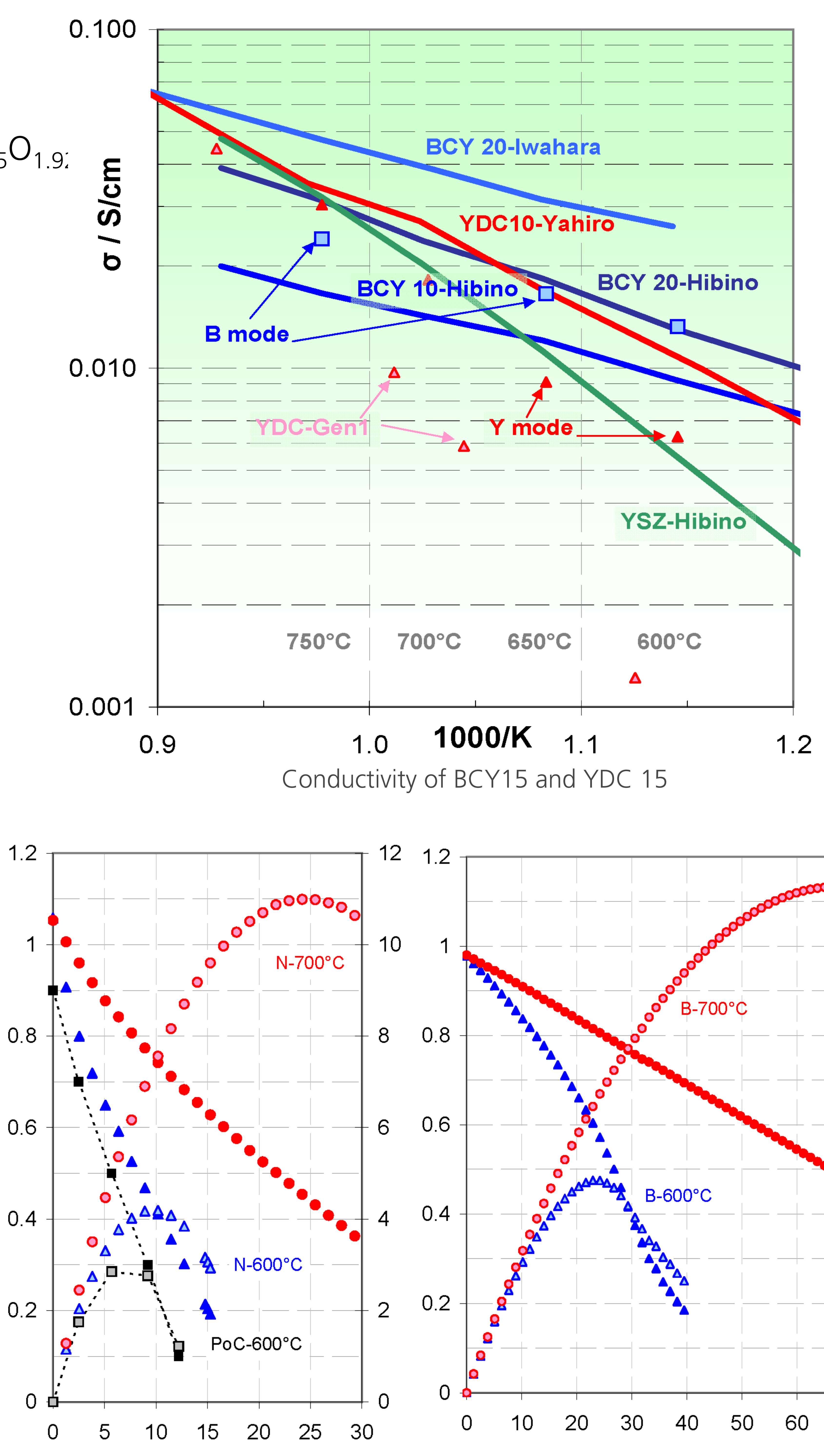

Current density $/ \mathrm{mA} / \mathrm{cm}^{2}$

$$
\text { Polarisation curves at different temperatures }
$$
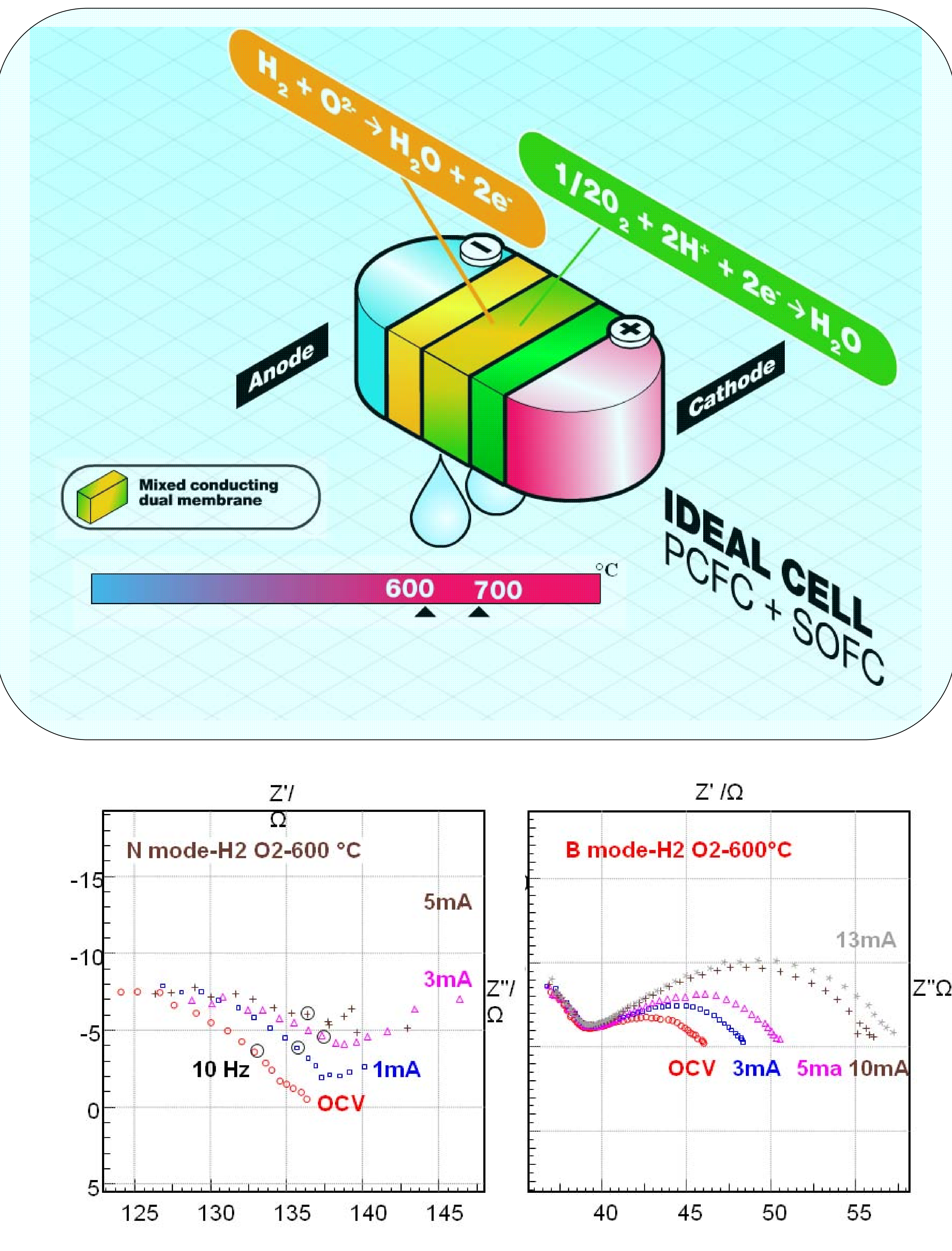

Complex impedance data at different electrical loading

\section{Conclusion and Outlook}

- stability and density of BCY15

should be improved

- measurements in 3 chamber set up

- $\mathrm{H}_{2} \mathrm{O}$ vapor measurement in gas chambers

- plasma spraying and wet powder spraying will be used to fabricate full cells with thinner electrolytes 